\title{
SHMT1 1420 and MTHFR 677 variants are associated with rectal but not colon cancer
}

\author{
Viktor Komlósi ${ }^{1}$, Erika Hitre ${ }^{2}$,Éva Pap ${ }^{2}$, Vilmos Adleff ${ }^{2}$, Andrea Réti ${ }^{2}$, Éva Székely ${ }^{3}$, Anna Bíró ${ }^{4}$, Péter Rudnai ${ }^{5}$, \\ Bernadette Schoket ${ }^{6}$, Judit Müller ${ }^{7}$, Béla Tóth ${ }^{8}$, Szabolcs Ottó ${ }^{2}$, Miklós Kásler ${ }^{2}$, Judit Kralovánszky² ${ }^{*}$, Barna Budai ${ }^{2}$
}

\begin{abstract}
Background: Association between rectal or colon cancer risk and serine hydroxymethyltransferase 1 (SHMT1) C1420T or methylenetetrahydrofolate reductase (MTHFR) C677T polymorphisms was assessed. The serum total homocysteine (HCY), marker of folate metabolism was also investigated.
\end{abstract}

Methods: The SHMT1 and MTHFR genotypes were determined by real-time PCR and PCR-RFLP, respectively in 476 patients with rectal, 479 patients with colon cancer and in 461 and 478, respective controls matched for age and sex. Homocysteine levels were determined by HPLC kit. The association between polymorphisms and cancer risk was evaluated by logistic regression analysis adjusted for age, sex and body mass index. The population stratification bias was also estimated.

Results: There was no association of genotypes or diplotypes with colon cancer. The rectal cancer risk was significantly lower for SHMT1 $\Pi(\mathrm{OR}=0.57,95 \%$ confidence interval $(\mathrm{Cl})$ 0.36-0.89) and higher for MTHFR CT genotypes (OR $=1.4,95 \% \mathrm{Cl} 1.06-1.84)$. A gene-dosage effect was observed for SHMT1 with progressively decreasing risk with increasing number of T allele $(p=0.014)$. The stratified analysis according to age and sex revealed that the association is mainly present in the younger ( $<60$ years) or male subgroup. As expected from genotype analysis, the SHMT1 T allele/MTHFR CC diplotype was associated with reduced rectal cancer risk (OR 0.56, $95 \% \mathrm{Cl}$ 0.42-0.77 vs all other diplotypes together). The above results are unlikely to suffer from population stratification bias. In controls HCY was influenced by SHMT1 polymorphism, while in patients it was affected only by Dukes' stage. In patients with Dukes' stage C or D HCY can be considered as a tumor marker only in case of SHMT1 1420CC genotypes.

Conclusions: A protective effect of SHMT1 1420T allele or SHMT1 1420 T allele/MTHFR 677 CC diplotype against rectal but not colon cancer risk was demonstrated. The presence of SHMT1 1420 T allele significantly increases the HCY levels in controls but not in patients. Homocysteine could be considered as a tumor marker in SHMT1 1420 wild-type (CC) CRC patients in Dukes' stage C and D. Further studies need to clarify why SHMT1 and MTHFR polymorphisms are associated only with rectal and not colon cancer risk.

\section{Background}

Colorectal cancer (CRC) is the second leading cause of cancer morbidity in Hungary both in male and female populations, and is one of the most frequent cause of cancer-related deaths. The mean age of the patients at the diagnosis of CRC is about 60 years and yearly about 9,000 new cases occur including approximately 2,800 newly diagnosed rectal cancer cases. Numerous results

\footnotetext{
* Correspondence: kralo@oncol.hu

${ }^{2}$ Department of Clinical Research, National Institute of Oncology, Budapest, Hungary

Full list of author information is available at the end of the article
}

have been accumulated suggesting the role of folate and folate-related enzyme polymorphisms in the etiology of CRC. Low folate intake or low bioavailability of circulating folate, key components of one-carbon metabolism, have been related to increased risk of CRC [1]. The results, however, are still not conclusive. In a recent report an opposite influence of folate on different stages of the adenoma-carcinoma sequence was documented [2]. On the other hand, there are studies providing evidence for the significance of genetic polymorphisms of folate-cycle enzymes (e.g. methylenetetrahydrofolate reductase (MTHFR)) in colorectal carcinogenesis [3].
C Biomed Central

C 2010 Komlósi et al; licensee BioMed Central Ltd. This is an Open Access article distributed under the terms of the Creative Commons Attribution License (http://creativecommons.org/licenses/by/2.0), which permits unrestricted use, distribution, and reproduction in any medium, provided the original work is properly cited. 
The role of the MTHFR C677T polymorphism influencing CRC susceptibility is also inconsistent $[4,5]$. In a meta-analysis of 25 studies Hubner et al. reported that MTHFR 677TT genotype is associated with a significant, but moderately reduced risk of CRC [6]. Another less widely studied enzyme of folate/one-carbon metabolism, the cytosolic serine hydroxymethyltransferase (SHMT1), has a frequent but functionally less characterized Leu- > Phe polymorphism (SNP variant C1420T). This polymorphism was associated with significantly reduced risk of acute lymphocytic leukemia [7] and malignant lymphoma [8], but not colorectal adenoma [9]. However, in a CRC study no evidence of gene influence on the risk or association of this polymorphism with folate or homocysteine (HCY) levels were found [10]. The modifying effect of SHMT1 C1420T polymorphism on CRC risk remained undecided [11,12].

Rectal and colon cancer differ in their histology, diagnosis, sensitivity to radiotherapy and prognosis as well [13]. The treatment of rectal cancer usually includes preoperative radiotherapy, while colon cancer is nonradiosensitive. Both types of cancer have similar and also different risk factors [14,15]. Low folate and/or excessive alcohol intake are risk factors for both disease, but the physical activity have different effect on their risk [14]. In a large prospective US cohort body mass index (BMI) was related to increased risk of colon, but not rectal cancer [16]. There are few studies investigating the genetic risk factors separately in rectal and colon cancer, showing net differences between rectal and colon cancer [17-19]. The inconsistent results of the previous studies examining the polymorphisms in CRC may arise from the fact that dissimilar proportions of rectal and colon cancer cases were included in the investigations. Based on this information ascertained above the separate investigation of rectal and colon cancer cases is reasonable.

The SHMT1 is a vitamin B6 dependent enzyme that catalyzes the reversible conversion of serine and tetrahydrofolate (THF) to glycine and 5,10-methylenetetrahydrofolate (5,10-MTHF), a reaction which provides onecarbon units for S-adenosylmethionine (SAM), and for purine and pyrimidine synthesis.

Methylenetetrahydrofolate reductase irreversibly converts 5,10-MTHF to 5-methyltetrahydrofolate (5methylTHF) using vitamin B2 as a cofactor. 5methylTHF is the most stable and abundant form of folate metabolites, which in turn is the methyl donor in the conversion of $\mathrm{HCY}$ into methionine. Decrease in MTHFR reductase activity could lead to impaired HCY catabolism. There are two common functional SNPs on the MTHFR gene, which are in close linkage: the C677T and the A1298C substitutions. The C677T polymorphism on the exon 4 results in an Ala- > Val substitution at codon 222. Compared to the MTHFR $677 \mathrm{C}$ homozygotes the TT and CT genotypes have $70 \%$ and $30 \%$ lower enzyme activity, respectively. The $677 \mathrm{~T}$ allele has been associated with elevated plasma HCY levels [20]. In contrast, the exact functional consequence of the A1298C polymorphism is not well defined, and because of the linkage the extent of its independent contribution remains inconclusive [21,22].

Homocysteine is a sulphur-containing amino acid, produced mainly by S-adenosyl-methionine mediated methylation reactions. It is well-known that the total serum homocysteine (HCY) level among others is influenced by gender (higher in males), age (increasing with ageing), BMI (increased in obese individuals) and renal function (increased in renal impairment) [23-25]. Moreover, its accumulation in the serum is related to a number of disease conditions: vascular disease, cancer, neural tube defect, etc [26]. HCY reflects the combined pool of free, albumin bound, reduced and oxidized forms of $\mathrm{HCY}$ in the blood. Remethylation of homocysteine by methionine synthase, a vitamin B12 dependent enzyme, is the major metabolic pathway. The HCY level is inversely associated with the folate level and was suggested to be a risk factor of cancers [27,28]. Moreover a study suggested the role of $\mathrm{HCY}$ as a tumor marker of CRC [27]. This finding led to the exclusion of HCY from our analysis of cancer risk to avoid an eventual bias.

The aim of our study was to separately analyze the risk of rectal and colon cancer in association with SHMT1 C1420T and MTHFR C677T polymorphisms. The effect of the studied polymorphisms on the serum total $\mathrm{HCY}$ levels was also investigated.

\section{Methods}

\section{Study population}

For this case-control study 955 patients with colorectal adenocarcinoma were included. Cases of colon and rectal cancers were 476 and 479 , respectively. The 461 and 478 sex and age matched healthy individuals recruited all across Hungary were considered as controls. Consecutive series of patients from all regions of the country diagnosed with rectal or colon tumors (Dukes' stage A, B, C and $D$ ) between 2001-2007 and who underwent surgery, radiotherapy and/or chemotherapy at the National Institute of Oncology (NIO) were included. This institute is one of the largest radiotherapy centre in Hungary therefore it treats higher number of rectal cancer patients than the average number treated elsewhere in Hungary. Out of the 24 patients with rectosigmoid lesion only 12 , who ever received radiotherapy, were enrolled in the rectal cancer group. Patients with previous history of cancer or with synchronous cancer were not included in the study. All patients with hyperhomocysteinemia ( $\mathrm{HCY}>35 \mu \mathrm{M})$ 
possibly due to any renal impairment were excluded. The cases with proven or suspected familial adenomatous polyposis or hereditary nonpolyposis colorectal cancer were also excluded. The control population comprised healthy blood donors, healthcare workers or non-cancer patients from different regions of the country. The body mass index (BMI) was recorded both for controls and patients.

Written informed consent was obtained from all patients and controls before enrolment or sample withdrawal. The study was approved by the Ethics Committee of NIO.

\section{Preparation of the samples}

Blood samples from patients and controls were collected after overnight fasting into EDTA (15\%) containing tubes. Peripheral blood mononuclear cells (PBMC) were isolated from the whole blood by Ficoll gradient. DNA from PBMC was extracted according to the manufacturer's instructions using Master Pure TM Genomic DNA Purification Kit (Epicentre Technologies, Madison, WI, USA). The aliquots of blood plasma were frozen within 10 minutes after blood sampling and stored at $-84^{\circ} \mathrm{C}$ for $\mathrm{HCY}$ determination according to the instructions of the HCY kit (Immundiagnostik AG, Bensheim, Germany).

\section{Genotyping and serum total homocysteine (HCY) determination}

The MTHFR C677T (rs1801133) genotypes were determined by PCR-RFLP in conformity with the method described by Frosst et al. [29]. About 10\% of the samples were re-examined by an investigator who had not attended the previous collection of data. There were no discrepancies in the results.

To determine the SHMT1 C1420T polymorphism (rs1979277) an allele discrimination method using fluorogenic 3'-minor groove binding (MGB) probes described by Skibola et al. was adapted [7]. The realtime PCR was performed in Rotorgene 2000 real-time cycler (Corbette Research, Mortlake, Australia). About $10 \%$ of the samples were parallel genotyped by real-time PCR and PCR-RFLP method using Eam1104I restriction enzyme (Fermentas Inc., Hanover, MD, USA). The discrepancy between the methods was below $1 \%$.

The HCY level was determined by HPLC technique applying the HCY kit (Immundiagnostik AG, Bensheim, Germany). The interassay variability (overall coefficient of variation, \%) of quality control samples was $4.4 \%$. In patients the HCY levels were determined prior to surgical intervention and/or (radio)chemotherapy in fasting state.

During the above processes the investigators were blinded from sample categories.

\section{Statistical analysis}

The means and proportions between cases and controls were compared by $t$ test and $\chi^{2}$ test for goodness-of-fit, respectively, except for $\mathrm{HCY}$ where Mann-Whitney $\mathrm{U}$ test was used. The difference in the distribution of diplotypes was analysed by pooling the groups with variant allele(s). Beside sex, the median age of 60 years was used as threshold for stratification. The association between polymorphisms and cancer risk was evaluated by logistic regression analysis adjusted for age, sex and BMI. In case of stratified analysis according to sex, age or BMI the adjustment was made for age and BMI, sex and BMI or age and sex, respectively. The results are given as odds ratio (OR) and 95\% confidence interval (95\% CI). Trends in the OR (gene dosage effect) were calculated by assigning ordinal values to the genotypes.

The Hardy-Weinberg equilibrium (HWE) was tested using the Haploview 4.1 software (Daly Lab at the Broad Institute, Cambridge, MA, USA).

The assumable potential impacts of population stratification bias in the studied population were estimated with the formulas of Lee and Wang [30]. The used formula is: $U=(G B)^{1 / 2}\left[(G B)^{1 / 2}+1\right]^{2}\left[(G B)^{1 / 2}+G\right]^{-1}\left[(G B)^{1 / 2}\right.$ $+B]^{-1}$, where $G=A_{H} A_{L}^{-1}\left(1-A_{L}\right)\left(1-A_{H}\right)^{-1}$ and $B=$ $\mathrm{D}_{\mathrm{H}} \mathrm{D}_{\mathrm{L}}^{-1} ; \mathrm{A}_{\mathrm{H}, \mathrm{L}}$ - highest and lowest allele frequency; $\mathrm{D}_{\mathrm{H}}$, $\mathrm{L}$ - highest and lowest disease rate. The effective OR should be higher than the calculated $U$ in order to have a result, which cannot be explained away by population stratification bias alone.

The SHMT1 C1420T genotype frequencies of European countries found in dbSNP [31], the MTHFR C677T genotype frequencies in Hungary presented in 12 independent publications and the colon and rectal cancer incidences in Europe [32] and in Hungary (National Cancer Registry for 2001-2007, I. Gaudi, personal communication) were used.

The age, sex, BMI and Dukes' stage adjusted HCY mean values in different geno- and diplotype groups were compared by Kruskal-Wallis ANOVA and Kruskal-Wallis $\mathrm{Z}$ post hoc test. The same analysis for different Dukes' stages was applied for HCY mean levels adjusted for age, sex and BMI. The linear trend was also tested for different Dukes' stages. The patients with Dukes' stage A, because of their low number, were included in the group with stage B.

All statistical tests were performed with NCSS software (Hintze, J. 2001. NCSS and PASS. Number Cruncher Statistical System, Kaysville, UT, http://www. ncss.com). A level of $5 \%$ or if the $95 \%$ CI did not include unity was considered significant.

\section{Results}

Selected characteristics and the genotype distributions of patients and controls are summarized in Table 1. 
Table 1 Selected characteristics and genotype frequencies of SHMT1 C1420T and MTHFR C677T polymorphisms of patients with colon cancer, rectal cancer and that of the respective controls

\begin{tabular}{|c|c|c|c|c|c|c|}
\hline \multirow[t]{3}{*}{ Parameters } & \multirow[t]{2}{*}{ Control } & Colon cancer & \multirow[t]{3}{*}{$\mathrm{p}$} & \multirow[t]{2}{*}{ Control } & Rectal cancer & \multirow[t]{3}{*}{$p$} \\
\hline & & $\mathrm{n}=476$ & & & $n=479$ & \\
\hline & n (\%) & & & n (\%) & & \\
\hline \multicolumn{7}{|l|}{ Age (years) } \\
\hline mean $\pm S D$ & $59.2 \pm 12.4$ & $59.5 \pm 11.9$ & 0.733 & $58.9 \pm 11.1$ & $58.9 \pm 10.5$ & 0.938 \\
\hline$<60$ & $230(50)$ & $226(47)$ & 0.300 & $246(51)$ & $238(50)$ & 0.437 \\
\hline$\geq 60$ & $231(50)$ & $250(53)$ & & $232(49)$ & $241(50)$ & \\
\hline \multicolumn{7}{|l|}{ Sex } \\
\hline male & $218(47)$ & $227(48)$ & 0.863 & $304(64)$ & $302(63)$ & 0.803 \\
\hline female & $243(53)$ & $249(52)$ & & $174(36)$ & $177(37)$ & \\
\hline \multicolumn{7}{|l|}{ BMl } \\
\hline mean $\pm S D$ & $26.2 \pm 3.9$ & $26.2 \pm 4.0$ & 1.000 & $26.5 \pm 3.5$ & $26.4 \pm 4.3$ & 0.882 \\
\hline \multicolumn{7}{|c|}{ Dukes' stage } \\
\hline A & & $3(1)$ & & & $3(1)$ & \\
\hline B & & $107(22)$ & & & $102(21)$ & \\
\hline C & & $181(38)$ & & & $220(46)$ & \\
\hline $\mathrm{D}$ & & $185(39)$ & & & $154(32)$ & \\
\hline \multicolumn{7}{|l|}{ SHMT1 C1420T } \\
\hline $\mathrm{CC}$ & $220(48)$ & $228(48)$ & 0.360 & $220(46)$ & $249(52)$ & 0.002 \\
\hline $\mathrm{CT}$ & $186(40)$ & $201(42)$ & & $198(41)$ & $192(40)$ & \\
\hline$\pi$ & $55(12)$ & 47 (10) & & $60(13)$ & $38(8)$ & \\
\hline $\mathrm{CT}+\mathrm{TT}$ & $241(52)$ & $248(52)$ & 0.939 & $258(54)$ & $230(48)$ & 0.009 \\
\hline \multicolumn{7}{|l|}{ MTHFR C677T* } \\
\hline $\mathrm{CC}$ & $216(47)$ & $208(44)$ & 0.396 & $226(47)$ & $190(40)$ & 0.002 \\
\hline$C T$ & $186(40)$ & $196(42)$ & & $194(41)$ & $231(48)$ & \\
\hline$\Pi$ & $59(13)$ & $68(14)$ & & $58(12)$ & $58(12)$ & \\
\hline$C T+\pi T$ & $245(53)$ & $264(56)$ & 0.230 & $252(53)$ & $289(60)$ & 0.001 \\
\hline \multicolumn{7}{|l|}{ SHMT1 /MTHFR } \\
\hline CC/CC & $89(19)$ & $93(20)$ & 0.160 & $91(19)$ & $103(22)$ & $<0.001$ \\
\hline $\mathrm{CC} / \mathrm{CT}+\mathrm{TT}$ & $131(29)$ & $132(28)$ & & $129(27)$ & $146(30)$ & \\
\hline $\mathrm{CT}+\mathrm{TT} / \mathrm{CC}$ & $127(28)$ & $115(24)$ & & $135(28)$ & 87 (18) & \\
\hline $\mathrm{CT}+\mathrm{TT} / \mathrm{CT}+\mathrm{TT}$ & $114(24)$ & $132(28)$ & & $123(26)$ & $143(30)$ & \\
\hline
\end{tabular}

Serum total homocysteine

$$
\text { mean } \pm \text { SD } 17.9 \pm 6.9 \quad 20.8 \pm 6.5
$$

$<0.0001$

$17.7 \pm 6.6$

$19.1 \pm 5.9$

$<0.0001$

* genotyping failed in 4 colon cancer patients

The HCY levels were significantly higher in cancer patients (mean \pm SE: $20.8 \pm 0.30 ; p<0.0001$ and 19.1 $\pm 0.27 ; \mathrm{p}<0.0001$ for colon and rectal cancer, respectively) than in controls $(17.9 \pm 0.32$ and $17.7 \pm 0.30)$ (Table 1). The distribution of SHMT1 C1420T and MTHFR C677T genotypes in controls and cases was in conformity with the HWE (SHMT1: controls $\mathrm{p}=0.131$ and colon cancer $\mathrm{p}=0.843$; controls $\mathrm{p}=0.167$ and rectal cancer $\mathrm{p}=0.973 ;$ MTHFR: controls $\mathrm{p}=0.074$ and colon cancer $\mathrm{p}=0.063$; controls $\mathrm{p}=0.126$ and rectal cancer $\mathrm{p}=0.403)$.

The univariate comparison of raw genotype distributions of cases and controls revealed significant difference only in case of rectal cancer for both SHMT1 C1420T and MTHFR C677T polymorphisms. An opposite distribution shift from variant homozygotes toward wild type and from wild type to hetorozygotes was present in case of SHMT1 and MTHFR, respectively, hence the SHMT1 CT+TT/MTHFR CC diplotypes were significantly underrepresented among cases with rectal cancer (Table 1). The distribution of unpooled diplotype groups is provided in the Additional file 1.

No association was observed in colon cancer for SHMT1 and MTHFR CT or TT genotypes compared with the CC genotype (Table 2). In contrast with colon cancer, the adjusted risk ratio for rectal cancer was significantly lower for SHMT1 TT and higher for MTHFR $\mathrm{CT}$ genotypes. A gene-dosage effect was observed only for SHMT1 with the progressively decreasing risk ratio with increasing number of $\mathrm{T}$ allele $(\mathrm{p}=0.014)$. 
Table 2 Overall, sex- and age-specific risk of colon and rectal cancer according to SHMT1 C1420T and MTHFR C677T polymorphisms

\begin{tabular}{|c|c|c|c|c|}
\hline & $\begin{array}{l}\text { Colon cancer } \\
\text { OR }^{*}(95 \% \mathrm{Cl})\end{array}$ & $p^{\dagger}$ & $\begin{array}{l}\text { Rectal cancer } \\
\text { OR* }^{*}(95 \% \mathrm{Cl})\end{array}$ & $p^{\dagger}$ \\
\hline \multicolumn{5}{|l|}{ SHMT11420 } \\
\hline CC & 1.00 (reference) & 0.611 & 1.00 (reference) & 0.014 \\
\hline CT & $1.07(0.81-1.41)$ & 0.62 & $0.86(0.66-1.13)$ & 0.27 \\
\hline$\pi$ & $0.86(0.56-1.33)$ & 0.49 & $0.57(0.36-0.89)$ & 0.013 \\
\hline $\mathrm{CT}+\mathrm{TT}$ & $1.02(0.79-1.32)$ & 0.90 & $0.80(0.62-1.03)$ & 0.08 \\
\hline \multicolumn{5}{|l|}{ MTHFR 677} \\
\hline CC & 1.00 (reference) & 0.338 & 1.00 (reference) & 0.083 \\
\hline CT & $1.08(0.81-1.42)$ & 0.61 & $1.40(1.06-1.84)$ & 0.016 \\
\hline$\pi$ & $1.19(0.80-1.78)$ & 0.39 & $1.14(0.75-1.73)$ & 0.53 \\
\hline $\mathrm{CT}+\mathrm{TT}$ & $1.11(0.87-1.44)$ & 0.43 & $1.35(1.04-1.74)$ & 0.024 \\
\hline
\end{tabular}

Males

SHMT11420

CT $\quad 0.93(0.63-1.39) \quad 0.73 \quad 0.92(0.65-1.29) \quad 0.63$

$\begin{array}{lllll}\pi & 0.75(0.40-1.39) & 0.36 & 0.42(0.23-0.75) & 0.003\end{array}$

$\begin{array}{lllll}C T+T T & 0.89(0.61-1.30) & 0.54 & 0.80(0.58-1.10) & 0.16\end{array}$

MTHFR 677

\begin{tabular}{rcccl} 
CC & 1.00 (reference) & 0.121 & 1.00 (reference) & \multicolumn{1}{c}{0.494} \\
CT & $1.36(0.91-2.05)$ & 0.14 & $1.45(1.03-2.05)$ & 0.034 \\
$\Pi T$ & $1.42(0.80-2.50)$ & 0.23 & $0.89(0.52-1.51)$ & 0.67 \\
CT+TT & $1.37(0.94-2.00)$ & 0.10 & $1.29(0.94-1.79)$ & 0.12
\end{tabular}

Females

SHMT11420

\begin{tabular}{rcccc} 
CC & 1.00 (reference) & 0.824 & 1.00 (reference) & 0.390 \\
$C T$ & $1.22(0.83-1.80)$ & 0.31 & $0.77(0.49-1.22)$ & 0.27 \\
$\Pi T$ & $0.94(0.50-1.74)$ & 0.83 & $0.97(0.47-2.01)$ & 0.93 \\
$C T+\Pi T$ & $1.13(0.79-1.62)$ & 0.50 & $0.80(0.52-1.22)$ & 0.29 \\
677 & & & & \\
$C C$ & 1.00 (reference) & 0.863 & 1.00 (reference) & 0.052 \\
$C T$ & $0.87(0.59-1.28)$ & 0.48 & $1.39(0.88-2.19)$ & 0.16 \\
$\Pi T$ & $1.07(0.60-1.90)$ & 0.82 & $1.81(0.91-3.60)$ & 0.09 \\
$C T+\Pi T$ & $0.93(0.65-1.33)$ & 0.68 & $1.45(0.94-2.23)$ & 0.09 \\
\hline
\end{tabular}

Age $<60$ years

SHMT11420

CC $\quad 1.00$ (reference)

CT $\quad 1.22(0.82-1.82) \quad 0.33$

$\pi \quad 0.67(0.37-1.23) \quad 0.19$

$\mathrm{CT}+\mathrm{TT} \quad 1.08(0.74-1.57) \quad 0.69$

MTHFR 677

CC 1.00 (reference)

CT $\quad 1.72(1.15-2.59)$

Tा $1.37(0.77-2.44)$

$\mathrm{CT}+\mathrm{TT} \quad 1.65(1.14-2.39)$

Age $\geq 60$ years

SHMT11420

$\begin{array}{rrr}C C & 1.00 \text { (reference) } & 0.943 \\ C T & 0.91(0.62-1.34) & 0.64 \\ T T & 1.13(0.59-2.18) & 0.71 \\ C T+T T & 0.92(0.64-1.33) & 0.67\end{array}$

0.4851 .00 (reference) $0.81(0.55-1.19)$

$0.32(0.16-0.61)$

$0.69(0.48-0.99)$

$0.047 \quad 1.00$ (reference) 0.008

0.29

0.008

$1.97(1.33-2.92)$

$1.67(1.16-2.40)$

1.00 (reference)

$0.90(0.61-1.32)$

$1.04(0.54-1.98)$

$0.92(0.64-1.31)$
$0.98(0.54-1.76)$
0.015

003

0.67

390

\section{diplotypes is provided in the Additional file 1.}

As the distribution of SHMT1 C1420T genotypes are not available for the Hungarian population the European genotype frequencies and rectal cancer incidences were used instead to gauge any potential population stratification bias. The SHMT1 $1420 \mathrm{CC}+\mathrm{CT}$ frequency in Europe ranges from 0.833 to 0.913 [31], the rectal cancer incidence ranges from approximately 9 to 37 per 100 000 inhabitants in different countries in Europe [32]. Using the formula of Lee and Wang it was found that the upper bound for the bias is 1.29 , which is less than

Table 3 Colon and rectal cancer risk based on SHMT1 1420/MTHFR 677 diplotypes

\begin{tabular}{|c|c|c|c|c|}
\hline \multirow{2}{*}{$\begin{array}{l}\text { Diplotypes } \\
\text { SHMT1/ } \\
\text { MTHFR }\end{array}$} & \multicolumn{2}{|c|}{ Colon cancer } & \multicolumn{2}{|c|}{ Rectal cancer } \\
\hline & $\begin{array}{l}\text { case/ } \\
\text { control }\end{array}$ & $\begin{array}{c}\mathrm{OR}^{*}(95 \% \\
\mathrm{Cl})\end{array}$ & $\begin{array}{l}\text { case/ } \\
\text { control }\end{array}$ & $\mathrm{OR}^{*}(95 \% \mathrm{Cl})$ \\
\hline $\mathrm{CC} / \mathrm{CC}$ & $93 / 89$ & $\begin{array}{c}1.00 \\
\text { (reference) }\end{array}$ & $103 / 91$ & $\begin{array}{c}1.00 \\
\text { (reference) }\end{array}$ \\
\hline $\mathrm{CC} / \mathrm{CT}+\mathrm{TT}$ & 132/131 & $\begin{array}{c}0.95(0.65- \\
1.39)\end{array}$ & $146 / 129$ & $\begin{array}{c}0.99(0.69- \\
1.44)\end{array}$ \\
\hline $\mathrm{CT}+\mathrm{TT} / \mathrm{CC}$ & $115 / 127$ & $\begin{array}{c}0.87(0.59- \\
1.27)\end{array}$ & $87 / 135$ & $\begin{array}{c}0.57(0.39- \\
0.84)^{\dagger}\end{array}$ \\
\hline $\mathrm{CT}+\mathrm{TT} / \mathrm{CT}+\mathrm{TT}$ & $132 / 114$ & $\begin{array}{c}1.10(0.75- \\
1.62)\end{array}$ & $143 / 123$ & $\begin{array}{c}1.02(0.71- \\
1.48)\end{array}$ \\
\hline
\end{tabular}

* adjusted for age, sex and $\mathrm{BMI}^{\dagger}{ }^{+}$different from reference $(\mathrm{p}=0.005)$ or $\mathrm{CT}$ $+\pi T / C T+\pi(p=0.002)$ 
$1 / 0.55=1.82$, the estimated odds ratio observed in our study for carriers of SHMT1 1420C allele in Hungary. In the case of MTHFR C677T, we have found 12 independent publications for the Hungarian population, thus the range of $\mathrm{CT}+\mathrm{TT}$ frequencies were in the range of 0.412-0.7. The rectal cancer incidence in Hungary ranges from approximately 32 to 38 per 100,000 individuals, thus the upper bound for the bias is 1.05 , which is less than 1.38 found for Hungarian MTHFR 677T allele carriers.

In order to investigate the effect of SHMT1 C1420T and MTHFR C677T polymorphisms the age, sex and BMI adjusted mean HCY levels in different diplotypes were compared in controls and patients. The HCY levels of patients were also adjusted for Dukes' stage, because the mean HCY levels were significantly higher in advanced stages of the disease (Table 4). In controls the presence of SHMT1 variant allele resulted in significantly higher HCY levels while this effect could not be observed in patients. The MTHFR $\mathrm{T}$ allele had no unequivocal effect on HCY levels. The adjusted mean HCY levels of all diplotypes are presented in the Additional file 1 .

\section{Discussion}

In our study both investigated polymorphisms, SHMT1 C1420T and MTHFR C677T, exert influence on the risk of rectal but not on that of colon cancer. Previous studies underline the capacity of SHMT1 C1420T polymorphism being directly related to cancer susceptibility. Skibola et al. found risk reduction for the SHMT1 $1420 \mathrm{TT}$ genotype in adult acute lymphocytic leukemia [7]. The same result was found by Hishida et al. in malignant lymphomas [8]. Recently, it was observed that in a North Chinese population there was a reduced risk of esophageal squamous cell carcinoma and gastric cardia adenocarcinoma in the case of SHMT1 1420CT heterozygotes compared to $C$ homozygotes [33]. In the above mentioned studies the risk reduction influenced by the presence of SHMT1 1420T allele was in accordance with our findings regarding rectal cancer. The variant SHMT1 enzyme may result in decreased production of 5,10-MTHF and accumulation of tetrahydrofolate, although the exact biological effect of this phenomenon or the complete mechanism leading to carcinogenesis is not yet known.

In a case-control study van den Donk et al. could not demonstrate association between colorectal adenoma risk and SHMT1 C1420T polymorphism. Unfortunately, the authors performed a stratified analysis according to sex and not to the adenoma localization [9].

Chen et al. could not prove any risk-reducing effect of the variant type SHMT1 C1420T polymorphism in case of CRC [10]. In his study only male cases and male hospital-based controls were used from Caucasian-American populations, but the rectal and colon cancer patients were not separately analyzed, thus the risk modifying effect of the SHMT1 C1420T polymorphism might be obscured. Guerreiro et al. found an increased risk of CRC in case of SHMT1 1420 C allele, although the strength of their observation is limited by the small number of variant homozygotes $(n=9)$ and moreover, the rectal and colon cancer patients were analyzed together [11]. Steck et al. found a borderline statistically significant decreased risk of colon cancer in whites, but not African Americans, with the SHMT 1420TT

Table 4 Mean serum total homocysteine levels according to Dukes' stage and SHMT1 1420/MTHFR 677 diplotypes in colon and rectal cancer patients and respective controls

\begin{tabular}{|c|c|c|c|c|}
\hline \multirow[b]{2}{*}{ Dukes' stage } & \multicolumn{4}{|c|}{ Mean serum total homocysteine* $(95 \% \mathrm{Cl})[\mu \mathrm{M}]$} \\
\hline & Control & Colon cancer & Control & Rectal cancer \\
\hline & $17.9(17.3-18.5)$ & & $17.7(17.1-18.3)$ & \\
\hline$A, B$ & & $19.4(16.9-21.8)$ & & $18.3(16.9-19.6)$ \\
\hline C & & $20.8(19.1-22.5)^{\circ}$ & & $19.1(17.9-20.2)^{\circ}$ \\
\hline $\mathrm{D}$ & & $21.6(20.7-22.6)^{\circ}$ & & $20.4(19.6-21.3)^{\circ}$ \\
\hline & & $p^{\dagger}=0.031$ & & $p^{\dagger}=0.036$ \\
\hline & & for trend $p=0.059$ & & for trend $p=0.053$ \\
\hline SHMT1/MTHFR & Control & Colon cancer** & Control & Rectal cancer** \\
\hline $\mathrm{CC} / \mathrm{CC}$ & $15.6(14.2-17.0)$ & $20.7(18.9-22.5)^{\circ}$ & $15.9(14.6-17.2)$ & $19.4(18.0-20.8)^{\circ}$ \\
\hline $\mathrm{CC} / \mathrm{CT}+\mathrm{TT}$ & $16.2(15.1-17.4)$ & $21.5(20.1-22.8)^{\circ}$ & $15.3(14.4-16.1)$ & $21.0(19.7-22.2)^{\circ}$ \\
\hline $\mathrm{CT}+\mathrm{TT} / \mathrm{CC}$ & $19.1(17.9-20.2)^{\#}$ & $22.8(21.0-24.5)^{\circ}$ & $19.3(18.1-20.5)^{\#}$ & $19.6(17.9-21.4)$ \\
\hline$C T+T T / C T+T T$ & $20.3(19.1-21.6)^{\#}$ & $21.4(19.8-23.0)$ & $19.8(18.6-21.0)^{\#}$ & $20.8(19.7-21.9)$ \\
\hline & $\mathrm{p}^{\dagger}<0.0001$ & $\mathrm{p}^{\dagger}=0.155$ & $\mathrm{p}^{\dagger}<0.0001$ & $p^{\dagger}=0.221$ \\
\hline
\end{tabular}

* adjusted for age, sex and BMl; ${ }^{* *}$ also adjusted for Dukes' stage; ${ }^{\dagger}$ Kruskal-Wallis one-way ANOVA;

\# different from $\mathrm{CC} / \mathrm{CC}$ or $\mathrm{CC} / \mathrm{CT}+\pi$, Z-value test $\mathrm{p}<0.05$; $^{\circ}$ different from control, Mann-Whitney U-test $\mathrm{p}<0.01$ 
genotype as compared to the $\mathrm{CC}$ genotype. High folate intake reduced the risk of colon cancer in all genotypes. In this study the control group for whites deviated strongly from HWE ( $\mathrm{p}=0.0042)$ [12].

The presence of the MTHFR 677T allele represented a higher rectal, but not colon cancer risk compared to $\mathrm{CC}$ homozygotes. The relationship of MTHFR C677T polymorphism and CRC risk based on the results of previous meta- and pooled analyses remains unclarified $[34,35]$. It has to be mentioned that most of the studies investigating the MTHFR C677T polymorphisms did not separate rectal and colon cancer patients [35]. Recently, Cao et al. found that in males, among MTHFR 677TT genotype carriers, the OR for colon cancer was 2.42 , but that of for rectal cancer was 0.52 [19]. Their result was similar to ours regarding males older than 60 years with ORs 1.4 and 0.9 for colon and rectal cancer, respectively. The differing genotype distribution of MTHFR C677T in Chinese and Caucasian, the different lifestyle, etc. may account for the more modest difference.

In accordance with the explanations raised by Guerreiro et al., - regarding the controversial results of previous published studies about the CRC risk modified by the interaction of folate intake and MTHFR 677 polymorphism -, we accept the following statement: the low folate intake and the presence of MTHFR 677T allele or TT genotype predicts if there is an increased risk of CRC, while on the contrary high/adequate folate intake results in a risk reduction if the variant allele is present [11]. In Hungary the folate intake is generally low [36], thus our result regarding the rectal cancer risk is in accordance with the previous statement, however, for colon cancer this relation can be found only in case of younger individuals ( $<60$ years). Iacopetta et al. demonstrated an increased proximal, but not distal CRC risk in the presence of MTHFR $677 \mathrm{~T}$ allele and low folate intake or older ( $\geq 65$ years) individuals. Possible reasons for the discrepancy between their and our findings might include the classification of cancers as colon or rectal and the investigated Australian population consisted not only of Caucasians [37].

In the present study the combination of the SHMT1 $1420 \mathrm{CT}+\mathrm{TT}$ and MTHFR $677 \mathrm{CC}$ genotypes was found to imply the lowest risk for rectal cancer. In a recent study an interactive influence of MTHFR C677T and SHMT1 C1420T polymorphisms in the risk of esophageal and gastric carcinomas was also observed [33]. Decreased activity of SHMT1 and the unaltered activity of MTHFR may result in a decreased amount of 5,10MTHF available for pyrimidine synthesis. The combination with the highest risk is characterized by high SHMT1 activity and decreased MTHFR activity, which resulted in an increased availability of folate for pyrimidine synthesis. The impact of the examined polymorphisms on the DNA methylation is very complex. The decreased activity of SHMT1 may lead to a decreased DNA methylation through a negative feedback chain accumulation of intermediers and decreased 5-methylTHF production.

Our study also suggests the role of gender differences in the etiology of rectal and colon cancer. Female hormones may influence the susceptibility for second primary colorectal cancer [38]. Moreover, a statistically significant association was found between the DNA mismatch repair gene $M S H 2-118 \mathrm{~T}>\mathrm{C}$ polymorphism and a strong family history of $\mathrm{CRC}$ and this association was seen only in female but not male CRC patients [39]. The age of onset of CRC may also be influenced by polymorphisms [40]. An age-specific association was also observed for colon cancer but not for rectal cancer in case of apolipoprotein E (apoE) polymorphism [41].

The association between BMI and colon cancer described in a previous large cohort and a pooled study $[16,42]$ was not demonstarted in our analysis, which could be due to the insufficient statistical power. The above studies also demonstrated sex-specific and agespecific associations.

Gauging the population stratification bias for both polymorphisms it can be concluded that our findings are unlikely to be biased. However, it should be considered that in case of SHMT1 the genotype distributions and CRC incidence used for calculations were not available for Hungarian, but only for the European Caucasian population.

Homocysteine is produced during the methionine dependent DNA methylation. For its remethylation the product of the MTHFR enzyme, the 5-methylTHF, is essential. The less important metabolic transformation of homocystein implies cystathion beta-synthase or liver betain-homocysteine methyltransferase. Considering the important functional role of SHMT1 in the production of methyl group for multiple metabolic pathways any disturbance in the protein expression due to the polymorphisms could result in the reduction of the available one-carbon units that is also necessary for the remethylation of homocysteine. Geisel et al. found non-significant elevated HCY levels in the SHMT1 1420TT group in senior healthy subjects [43]. Chen et al. reported significantly higher HCY levels in case of SHMT1 1420 CT genotypes in a study including healthy male subjects [10]. Similarly, in our study the presence of SHMT 1420 $\mathrm{T}$ allele significantly increased the $\mathrm{HCY}$ levels in controls. In relative young healthy individuals (20-40 years) Pereira et al. [21] and Baily et al. [22] found significantly higher HCY levels in MTHFR 677 TT genotypes compared to the other genotypes. Almost the same result was found by Semmler et al. [44] with the exception that the above association could not be demonstrated 
for older individuals ( $>55$ years). This latter data support our results that in controls (mean age 59 years) there were no association between HCY levels and MTHFR 677 polymorphism.

The influence of the investigated polymorphisms on $\mathrm{HCY}$ levels in case of patients may be obscured because of the much narrow distribution of HCY levels (coefficient of variation lowered by $\sim 20 \%$ ) than in controls. The effect is likely to be in a relationship with a yet unclarified HCY-increasing mechanism. Proliferating tumor cells appear to be the main cause of accumulation of HCY and thus, the development of hyperhomocysteinaemia in cancer patients [45]. The tumor marker character of the HCY, namely the elevated HCY levels in cancer patients [45-54], the elevated HCY levels in advanced clinical stages $[49,53]$ and the usefulness of $\mathrm{HCY}$ to monitor therapeutic effects $[48,49,54,55]$ has also been demonstrated. Moreover, HCY concentration followed CEA levels in CRC patients [55]. This effect might be strongly related to the malignant disease progression as in our study the HCY gradually increased with the lymph node involvement (Dukes' stage C) and further on with the presence of distant metastases (Dukes' stage D).

In our study it seems at a first glance that HCY in Dukes' stage $\mathrm{C}$ and $\mathrm{D}$ is a tumor marker as it was suggested by Wu et al. [27], but if the SHMT1 1420 polymorphism is taken into account then HCY can be considered as tumor marker only in case of wild (CC) genotypes. This fact remains valid even for patients of Dukes' D stage presenting the highest HCY levels (data not shown). Similarly, Battistelli et al. presented significantly elevated $\mathrm{HCY}$ levels compared to controls only in case of MTHFR $677 \mathrm{CC}+\mathrm{CT}$ genotypes [50].

An interesting question would be why the $\mathrm{HCY}$ levels of rectal cancer patients in case of the "lowest rectal cancer risk"-presenting diplotype are not significantly higher compared to that of the controls as it can be seen in case of colon cancers. Could an unknown HCYlowering mechanism confer resistance in this context against rectal carcinogenesis? Based on present results, it might be supposed, that in case of the risk-reducing diplotypes the low $\mathrm{HCY}$ compared to controls is directly responsible for reduced risk. On the other hand the low $\mathrm{HCY}$ could be an ancillary result and other mechanisms may lead to the reduced risk. Recently it was demonstrated [56] that if the variant SHMT1 is localized in the nucleus only an impaired de novo thymidylate biosynthesis is assured. The thymidylate biosynthesis is further diminished by the wild-type-MTHFR-transformed and thus depleted 5,10-MTHF levels. The impaired thymidylate biosynthesis is unfavourable for cell proliferation. These results suggest that the association between the elevated HCY levels and the cancer risk is not obvious and first of all the "tumor marker" aspect of HCY needs to be underlined.

\section{Conclusions}

This is the first study presenting the protective effect of SHMT1 1420T allele or SHMT1 $1420 \mathrm{~T}$ allele/MTHFR 677 CC diplotype against rectal cancer risk. SHMT1 1420 variant significantly increase HCY levels in controls but not patients. HCY could be considered tumor marker only in wild-type (CC) SHMT1 1420 CRC patients in Dukes' stage C and D. Higher HCY levels are characteristics of patients in advanced stages of the disease. Further studies need to be conducted to reveal the complex role of SHMT1, MTHFR and other folate enzyme polymorphisms in colon and rectal carcinogenesis. The importance of HCY level also need to be clarified.

\section{Additional material}

Additional file 1: Distribution, cancer risk and serum total

homocysteine level of diplotypes. This file contains the distribution,

cancer risk (OR and 95\% Cl) and mean serum total homocysteine (95\%

Cl) level of unpooled SHMT1 1420/MTHFR 677 diplotypes.

\section{Acknowledgements}

This study was supported by the National Research and Development Programme (NKFP1-00024/2005) grant. Authors are grateful to I. Gaudi for statistical support and to the co-workers of the Department of Human and Experimental Pathology of the NIO, Budapest, Hungary for the histopathological staging of the patients. The assistance of Dr. A. Hajnal, Serologic Laboratory of the National Blood Transfusion Service, Budapest, Hungary in providing control blood samples is acknowledged.

\section{Author details}

${ }^{1}$ School of PhD studies, Pathological Sciences, Semmelweis University, Budapest, Hungary. ${ }^{2}$ Department of Clinical Research, National Institute of Oncology, Budapest, Hungary. ${ }^{3}$ Medical Department, "Szent István és Szent László" Hospital, Budapest, Hungary. ${ }^{4}$ Department of Cytogenetics and Immunology, National Institute of Chemical Safety, Budapest, Hungary. ${ }^{5}$ Department of Environmental Epidemiology, National Institute of Environmental Health, Budapest, Hungary. ${ }^{6}$ Department of Molecular Environmental Epidemiology, National Institute of Environmental Health, Budapest, Hungary. ${ }^{7}$ Second Department of Pediatrics, Semmelweis University, Budapest, Hungary. ${ }^{8}$ Department of Dermatology, Venerology and Dermatooncology, Semmelweis University, Budapest, Hungary.

\section{Authors' contributions}

VK, VA and BB carried out the molecular genetic studies, ÉP and AR carried out the HPLC assays, VK, JK and BB participated in the design of the study and helped to draft the manuscript, EH, ÉS, AB, PR, BS and BT participated in the enrollment and conduct of the study, JM, SO and MK participated in study coordination and revised the manuscript, VK and BB conceived the study, participated in its design and statistical analyses. All authors read and approved the final manuscript.

\section{Competing interests}

The authors declare that they have no competing interests.

Received: 16 March 2010 Accepted: 4 October 2010

Published: 4 October 2010 


\section{References}

1. Giovannucci E: Epidemiologic studies of folate and colorectal neoplasia: a review. J Nutr 2002, 132:2350S-2355S.

2. van Guelpen B, Hultdin J, Johansson I, Hallmans G, Stenling R, Riboli E, Winkvist A, Palmqvist R: Low folate levels may protect against colorectal cancer. Gut 2006, 55:1461-1466.

3. Sharp $L$, Little J: Polymorphisms in genes involved in folate metabolism and colorectal neoplasia: a HuGE review. Am J Epidemiol 2004, 159:423-443.

4. Ulvik A, Vollset SE, Hansen S, Gislefoss R, Jellum E, Ueland PM: Colorectal cancer and the methylenetetrahydrofolate reductase $677 \mathrm{C}->\mathrm{T}$ and methionine synthase $2756 \mathrm{~A}->\mathrm{G}$ polymorphisms: a study of 2,168 casecontrol pairs from the JANUS cohort. Cancer Epidemiol Biomarkers Prev 2004, 13:2175-2180.

5. Chen K, Jiang QT, He HQ: Relationship between metabolic enzyme polymorphisms and colorectal cancer. World J Gastroenterol 2005, 11:331-335.

6. Hubner RA, Houlston RS: MTHFR C677T and colorectal cancer risk: a meta-analysis of 25 populations. Int J Cancer 2006, 120:1027-1035.

7. Skibola CF, Smith MT, Hubbard A, Shane B, Roberts AC, Law GR, Rollinson S, Roman E, Cartwright RA, Morgan GJ: Polymorphisms in the thymidylate synthase and serine hydroxymethyltransferase genes and risk of adult acute lymphocytic leukemia. Blood 2002, 99:3786-3791.

8. Hishida A, Matsuo K, Hamajima N, Ito H, Ogura M, Kagami Y, Taji H, Morishima $Y$, Emi N, Tajima K: Associations between polymorphisms in the thymidylate synthase and serine hydroxymethyltransferase genes and susceptibility to malignant lymphoma. Haematologica 2003 88:159-166.

9. van den Donk M, Visker MH, Harryvan JL, Kok FJ, Kampman E: Dietary intake of B-vitamins, polymorphisms in thymidylate synthase and serine hydroxymethyltransferase 1, and colorectal adenoma risk: a Dutch casecontrol study. Cancer Lett 2007, 250:146-153.

10. Chen J, Kyte C, Valcin M, Chan W, Wetmur JG, Selhub J, Hunter DJ, Ma J: Polymorphisms in the one-carbon metabolic pathway, plasma folate levels and colorectal cancer in a prospective study. Int J Cancer 2004, 110:617-620.

11. Guerreiro CS, Cravo M, Costa AR, Miranda A, Tavares L, Moura-Santos P, MarquesVidal P, Nobre Leitão C: Risk of colorectal cancer associated with the C677T polymorphism in 5,10-methylenetetrahydrofolate reductase in Portuguese patients depends on the intake of methyl-donor nutrients. Am J Clin Nutr 2008, 88:1413-1418.

12. Steck SE, Keku T, Butler LM, Galanko J, Massa B, Millikan RC, Sandler RS: Polymorphisms in methionine synthase, methionine synthase reductase and serine hydroxymethyltransferase, folate and alcohol intake, and colon cancer risk. J Nutrigenet Nutrigenomics 2008, 1:196-204.

13. Kapiteijn E, Liefers GJ, Los LC, Kranenbarg EK, Hermans J, Tollenaar RA, Moriya Y, van de Velde CJ, van Krieken JH: Mechanisms of oncogenesis in colon versus rectal cancer. J Pathol 2001, 195:171-178.

14. Howard RA, Freedman DM, Park Y, Hollenbeck A, Schatzkin A, Leitzmann MF: Physical activity, sedentary behavior, and the risk of colon and rectal cancer in the NIH-AARP Diet and Health Study. Cancer Causes Controls 2008, 19:939-953.

15. Frattini $M$, Balestra $D$, Suardi $S$, Oggionni M, Alberici $P$, Radice $P$, Costa A, Daidone MG, Leo E, Pilotti S, Bertario L, Pierotti MA: Different genetic features associated with colon and rectal carcinogenesis. Clin Cancer Res 2004, 10:4015-4021.

16. Adams KF, Leitzmann MF, Albanes D, Kipnis V, Mouw T, Hollenbeck A Schatzkin A: Body mass and colorectal cancer risk in the NIH-AARP Cohort. Am J Epidemiol 2007, 166:36-45.

17. Le Marchand L, Wilkens LR, Kolonel LN, Henderson BE: The MTHFR C677T polymorphism and colorectal cancer: the multiethnic cohort study. Cancer Epidemiol Biomarkers Prev 2005, 14:1198-1203.

18. Kim DH, Ahn YO, Lee BH, Tsuji E, Kiyohara C, Kono S: Methylenetetrahydrofolate reductase polymorphism, alcohol intake, and risks of colon and rectal cancers in Korea. Cancer Lett 2004, 216:199-205.

19. Cao HX, Gao CM, Takezaki T, Wu JZ, Ding JH, Liu YT, Li SP, Su P, Cao J, Hamajima N, Tajima K: Genetic polymorphisms of methylenetetrahydrofolate reductase and susceptibility to colorectal cancer. Asian Pac J Cancer Prev 2008, 9:203-208.

20. Gudnason V, Stansbie D, Scott J, Bowron A, Nicaud V, Humphries S: C677T (thermolabile alanine/valine) polymorphism in methylenetetrahydrofolate reductase (MTHFR): its frequency and impact on plasma homocysteine concentration in different European populations. EARS group. Atherosclerosis 1998, 136:347-354.

21. Pereira AC, Schettert IT, Morandini AAF, Guerra-Shinohara EM, Krieger JE: Methylenetetrahydrofolate reductase (MTHFR) c677t gene variant modulates the homocysteine folate correlation in a mild folate deficient population. Clin Chim Acta 2004, 340:99-105.

22. Bailey LB, Duhaney RL, Maneval DR, Kauwell GP, Quinlivan EP, Davis SR, Cuadras A, Hutson AD, Gregory JF: Vitamin B-12 status is inversely associated with plasma homocysteine in young women with C677T and/or A1298C methylenetetrahydrofolate reductase polymorphisms. J Nutr 2002, 132:1872-1878.

23. Sassi S, Cosmi B, Palareti G, Legnani C, Grossi G, Musolesi S, Coccheri S: Influence of age, sex and vitamin status on fasting and post-methionine load plasma homocysteine levels. Haematologica 2002, 87:957-964.

24. Marchesini G, Manini R, Bianchi G, Sassi S, Natale S, Chierici S, Visani F, Baraldi L, Forlani G, Melchionda N: Homocysteine and psychological traits: a study in obesity. Nutrition 2002, 18:403-407.

25. Parsons DS, Reaveley DA, Pavitt DV, Brown EA: Relationship of renal function to homocystein and lipoprotein(a) levels: The frequency of the combination of both risk factors in chronic renal impairment. Am J Kidney Dis 2002, 40:916-923.

26. Valik D, Radina M, Sterba J, Vojtesek B: Homocysteine: exploring its potential as a pharmacodynamic biomarker of antifolate chemotherapy. Pharmacogenomics 2004, 5:1151-1162

27. Wu LL, Wu JT: Hyperhomocysteinemia is a risk factor for cancer and a new potential tumor marker. Clin Chim Acta 2002, 322:21-28.

28. Oikawa S, Murakami K, Kawanishi S: Oxidative damage to cellular and isolated DNA by homocysteine: implications for carcinogenesis. Oncogene 2003, 22:3530-3538.

29. Frosst P, Blom HJ, Milos R, Goyette P, Sheppard CA, Matthews RG, Boers GJH, den Heijer M, Kluijtmans LAJ, van den Heuve LP, Rozen R: A candidate genetic risk factor for vascular disease: a common mutation in methylenetetrahydrofolate reductase. Nat Genet 1995, 10:111-113.

30. Lee WC, Wang LY: Simple formulas for gauging the potential impacts of population stratification bias. Am J Epidemiol 2007, 167:86-89.

31. Database of Single Nucleotide Polymorphisms (dbSNP). Bethesda (MD): National Center for Biotechnology Information, National Library of Medicine. dbSNP accession: \{rs1979277 and rs1801133\}, (dbSNP Build ID: 129) [http://www.ncbi.nlm.nih.gov/SNP/]

32. Ferlay J, Bray F, Pisani P, Parkin DM: GLOBOCAN 2002: Cancer incidences, mortality and prevalence worldwide. IARC Cancer Base No. 5 version 2.0. Lyon, France: IARC Press 2004.

33. Wang Y, Guo W, He Y, Chen Z, Wen D, Zhang X, Wang N, Li Y, Ge H, Zhang J: Association of MTHFR C677T and SHMT(1) C1420T with susceptibility to ESCC and GCA in a high incident region of Northern China. Cancer Causes Control 2007, 18:143-152.

34. Taioli E, Garza MA, Ahn YO, Bishop DT, Bost J, Budai B, Chen K, Gemignani F, Keku T, Lima CSP, Le Marchand L, Matsuo K, Moreno V, Plaschke J, Pufulete M, Thomas SB, Toffoli G, Wolf CR, Moore CG, Little J: Meta- and pooled analyses of methylenetetrahydrofolate reductase (MTHFR) C677T polymorphism and colorectal cancer: a HuGE-GSEC review. Am J Epidemiol 2009, 170:1207-1221.

35. Huang $Y$, Han S, Li Y, Mao Y, Xie Y: Different roles of MTHFR C677T and A1298C polymorphisms in colorectal adenoma and colorectal cancer: a meta-analysis. J Hum Genet 2007, 52:73-85.

36. Zajkás G, Bíró L, Greiner E, Szórád I, Ágoston H, Balázs A, Vitrai J, Hermann D, Boros J, Németh R, Kéki Z, Martos É: Dietary survey in Hungary, 2003-2004. Micronutrients: vitamins. Orv Hetil 2007, 148:1593-1600.

37. lacopetta B, Heyworth J, Girschik J, Grieu F, Clayforth C, Fritschi L: The MTHFR C677T and $\triangle$ DNMT3B C-149T polymorphism confer different risks for right- and left-sided colorectal cancer. Int J Cancer 2009, 125:84-90

38. Liang W: Age sex and the risk of grade-specific second primary colorectal cancer: Evidence for the protective effect of female hormone. Eur J Cancer 2007, 43:1856-1861.

39. Mrkonjic M, Raptis S, Green RC, Monga N, Daftary D, Dicks E, Younghusband HB, Parfrey PS, Gallinger SS, McLaughlin JR, Knight JA, Bapat B: MSH2 118T > C and MSH6 159C > T promoter polymorphisms and the risk of colorectal cancer. Carcinogenesis 2007, 28:2575-2580. 
40. Talseth BA, Ashton KA, Meldrum C, Suchy J, Kurzawski G, Lubinski J, Scott RJ: Aurora-A and Cyclin D1 polymorphisms and the age of onset of colorectal cancer in hereditery nonpoliposis colorectal cancer. Int $J$ Cancer 2007, 122:1273-1277.

41. Slattery ML, Sweeney C, Murtaugh M, Ma KN, Potter JD, Levin TR, Samowitz W, Wolff R: Associations between apoE genotype and colon and rectal cancer. Carcinogenesis 2005, 26:1422-1429.

42. Jacobs ET, Ahnen DJ, Ashbeck EL, Baron JA, Greenberg ER, Lance P, Lieberman DA, Mckeown-Eyssen G, Schatzkin A, Thompson PA, Martínez ME: Association between body mass index and colorectal neoplasia at follow-up colonoscopy: a pooling study. Am J Epidemiol 2009, 169:657-666

43. Geisel J, Hübner U, Bodis M, Schorr H, Knapp JP, Obeid R, Herrmann W: The role of genetic factors in the development of hyperhomocysteinemia. Clin Chem Lab Med 2003, 41:1427-1434.

44. Semmler A, Moskau S, Stoffel-Wagner B, Weller M, Linnebank M: The effect of MTHFR c.677C > T on plasma homocysteine levels depends on health, age and smoking. Clin Invest Med 2009, 32:E310-E314.

45. Schroecksnadel K, Frick B, Fiegl M, Winkler C, Denz HA, Fuchs D: Hyperhomocysteinaemia and immune activation in patients with cancer. Clin Chem Lab Med 2007, 45:47-53.

46. Ferroni P, Palmirotta R, Martini F, Riondino S, Savonarola A, Spila A, Ciatti F, Sini V, Mariotti S, Del Monte G, Roselli M, Guadagni F: Determinants of homocysteine levels in colorectal and breast cancer patients. Anticancer Res 2009, 29:4131-4138.

47. Almadori G, Bussu F, Galli J, Cadoni G, Zappacosta B, Persichilli S, Minucci A, Giardina B: Serum folate and homocysteine levels in head and neck squamous cell carcinoma. Cancer 2002, 94:1006-1011.

48. Refsum $H$, Wesenberg F, Ueland PM: Plasma homocysteine in children with acute lymphoblastic leukemia: changes during a chemotherapeutic regimen including methotrexate. Cancer Res 1991, 51:828-835.

49. Ozkan Y, Yardim-Akaydin S, Firat H, Calişkan-Can E, Ardiç S, Simşek B: Usefulness of homocysteine as a cancer marker: total thiol compounds and folate levels in untreated lung cancer patients. Anticancer Res 2007, 27:1185-1189.

50. Battistelli S, Vittoria A, Stefanoni M, Bing C, Roviello F: Total plasma homocysteine and methylenetetrahydrofolate reductase C677T polymorphism in patients with colorectal carcinoma. World J Gastroenterol 2006, 12:6128-6132.

51. Eleftheriadou A, Chalastras T, Ferekidou E, Yiotakis I, Kyriou L, Tzagarakis M Ferekidis E, Kandiloros D: Association between squamous cell carcinoma of the head and neck and serum folate and homocysteine. Anticancer Res 2006, 26:2345-2348.

52. Zacho J, Yazdanyar S, Bojesen SE, Tybjærg-Hansen A, Nordestgaard BG: Hyperhomocysteinemia, methylenetetrahydrofolate reductase c.677C > T polymorphism, and risk of cancer: cross-sectional and prospective studies and meta-analyses of 75,000 cases and 93,000 controls. Int J Cancer 2010

53. Gatt A, Makris A, Cladd H, Burcombe RJ, Smith JM, Cooper P, Thompson D, Makris M: Hyperhomocysteinemia in women with advanced breast cancer. Int I Lab Hematol 2007, 29:421-425.

54. Ruud E, Holmstrøm H, Brosstad F, Wesenberg F: Diagnostic value of family histories of thrombosis to identify children with thrombophilia. Pediatr Hematol Oncol 2005, 22:453-462.

55. Melichar B, Kalábová H, Krcmová L, Kasparová M, Malírová E, Melicharová K, Pecka M, Hyspler R, Solichová D: Serum homocysteine, cholesterol, retinol, alpha-tocopherol, glycosylated hemoglobin and inflammatory response during therapy with bevacizumab, oxaliplatin, 5 -fluorouracil and leucovorin. Anticancer Res 2009, 29:4813-4820.

56. Anderson DD, Stover PJ: SHMT1 and SHMT2 are functionally redundant in nuclear de novo thymidylate biosynthesis. PLOS ONE 2009, 4:e5839.

\section{Pre-publication history}

The pre-publication history for this paper can be accessed here: http://www.biomedcentral.com/1471-2407/10/525/prepub

doi:10.1186/1471-2407-10-525

Cite this article as: Komlósi et al: SHMT1 1420 and MTHFR 677 variants are associated with rectal but not colon cancer. BMC Cancer 2010 10:525.

\section{Submit your next manuscript to BioMed Central and take full advantage of:}

- Convenient online submission

- Thorough peer review

- No space constraints or color figure charges

- Immediate publication on acceptance

- Inclusion in PubMed, CAS, Scopus and Google Scholar

- Research which is freely available for redistribution

Submit your manuscript at www.biomedcentral.com/submit 